\title{
Scl-Ab reverts pro-osteoclastogenic signalling and resorption in estrogen deficient osteocytes
}

\author{
H. Allison ${ }^{1}$, G. Holdsworth ${ }^{2}$ and L. M. McNamara ${ }^{1 *}$
}

\begin{abstract}
Background: Neutralising antibodies to sclerostin ( $\mathrm{Scl}-\mathrm{Ab}$ ) have shown significant potential to induce bone formation and decrease bone resorption, increase strength and substantially reduce fracture risk in animal studies and clinical trials. Mechanical loading negatively regulates sclerostin expression, and sclerostin has been shown to induce RANKL synthesis in osteocytes. However, how Scl-Ab governs osteocyte regulation of osteoclast differentiation and function is not fully understood. We have recently discovered that osteoblasts and osteocytes alter osteoclastogenic signalling (RANKL/OPG) during estrogen-deficiency, and that osteoblast-induced osteoclastogenesis and resorption are exacerbated. However, it is not known whether estrogen deficient osteocytes exacerbate osteoclastogenesis. The aims of this study were to (1) establish whether osteocytes induce osteoclastogenesis and bone resorption during estrogen deficiency in vitro (2) investigate whether the sclerostin antibody can revert osteocyte-mediated osteoclastogenesis and resorption by attenuating RANKL/OPG expression.

Results: Using conditioned media and co-culture experiments we found increased osteocyte-induced osteoclastogenesis and bone resorption in estrogen deficient conditions. This is the first study to report that administration of Scl-Ab has the ability to revert osteocyte-mediated osteoclastogenesis and resorption by decreasing RANKL/OPG ratio expression and increasing WISP1 expression in estrogen deficient osteocytes.

Conclusions: This study provides an enhanced understanding of the biological changes underpinning decreases in bone resorption following Scl-Ab treatment observed in vivo by revealing that Scl-Ab can reduce proosteoclastogenic cell signalling between osteocytes and osteoclasts.
\end{abstract}

Keywords: Mechanobiology, Estrogen deficiency, Sclerostin antibody, Osteoclastogenesis, Oscillatory fluid flow

\footnotetext{
*Correspondence: laoise.mcnamara@nuigalway.ie

${ }^{1}$ Mechanobiology and Medical Devices Research Group (MMDRG), Centre for Biomechanics Research (BioMEC), Biomedical Engineering, College of

Engineering and Informatics, National University of Ireland Galway, Galway, Ireland

Full list of author information is available at the end of the article
}

(c) The Author(s). 2020 Open Access This article is licensed under a Creative Commons Attribution 4.0 International License, which permits use, sharing, adaptation, distribution and reproduction in any medium or format, as long as you give appropriate credit to the original author(s) and the source, provide a link to the Creative Commons licence, and indicate if changes were made. The images or other third party material in this article are included in the article's Creative Commons licence, unless indicated otherwise in a credit line to the material. If material is not included in the article's Creative Commons licence and your intended use is not permitted by statutory regulation or exceeds the permitted use, you will need to obtain permission directly from the copyright holder. To view a copy of this licence, visit http://creativecommons.org/licenses/by/4.0/ The Creative Commons Public Domain Dedication waiver (http://creativecommons.org/publicdomain/zero/1.0/) applies to the data made available in this article, unless otherwise stated in a credit line to the data. 


\section{Background}

Bone loss during postmenopausal osteoporosis is primarily attributed to osteoclast resorption [1], and for this reason anti-resorptive therapies, such as bisphosphonates, are widely used to inhibit osteoclast function and prevent bone loss [2]. However, anti-resorptive therapies only reduce fracture susceptibility by up to $50 \%$ [3]. Anabolic therapies have emerged, which promote new bone formation by targeting osteoblast and osteocyte activity [4-6]. In particular, neutralising antibodies to sclerostin (Scl-Ab) have shown significant potential to induce new bone formation, increase bone mass and strength, and substantially reduce fracture risk in animal studies and clinical trials [4, 7-11]. Moreover, the Scl$\mathrm{Ab}$ also decreases bone resorption in an indirect fashion $[4,9,12]$, yet the cellular changes underpinning this effect are not fully understood.

Osteocytes are the primary mechanosensors in bone, and it is thought that they are able to detect mechanical stimuli using mechanosensitive proteins, such as primary cilia, gap junctions and integrins [13-15], and transduce mechanical stimuli into biochemical responses $[16,17]$. Osteocytes regulate bone remodelling by signalling to both osteoblasts and osteoclasts via soluble paracrine factors, and direct cell-cell contact [18]. RANKL is a cytokine produced by osteocytes, osteoblasts and stromal cells, which induces osteoclastogenesis in cells of the monocyte/macrophage lineage [19-21]. OPG is also produced by osteocytes, osteoblasts and stromal cells, and acts as a decoy receptor for RANKL and thereby inhibits osteoclastogenesis [22]. Thus, the ratio of RANKL and OPG in bone is a major determinant of bone mass and strength $[23,24]$. In vitro studies have demonstrated that mechanically stimulating MLO-Y4 cells leads to decreases in RANKL/OPG ratio and a reduction in osteoclastogenesis when co-cultured with RAW264.7 and BMM cells [25-27]. Estrogen plays a role in osteocyte mechanosensation; in vitro studies have demonstrated that estrogen treated MLO-Y4 cells exhibited increased NOS activity, $\mathrm{NO}$ and $\mathrm{PGE}_{2}$ release, as well as increased intracellular calcium $\left[\mathrm{Ca}^{2+}\right]$ oscillations in response to fluid flow [28]. Interestingly, biochemicals $\mathrm{NO}$ and $\mathrm{PGE}_{2}$ are known to promote bone formation and inhibit osteoclast activity [29-31]. However, when estrogen was withdrawn from MLO-Y4 cells or the estrogen receptor chemically inhibited, intracellular $\left[\mathrm{Ca}^{2+}\right]$ calcium oscillations and the downstream responses to fluid flow were reduced [28]. Moreover, the putative osteocyte integrin $\alpha_{v} \beta_{3}$ mechanosensor is affected in estrogen deficient conditions both in vivo and in vitro. In vivo the number of $\beta_{3}$ integrin-positive osteocytes was reduced in cortical bone of ovariectomised (OVX) rats compared to SHAM animals [32]. In vitro estrogen deficient MLO-Y4 cells have been shown to have smaller focal adhesion area with reduced $\alpha_{v} \beta_{3}$ localisation [27]. Furthermore, the estrogen deficient MLO-Y4 cells displayed an increase in RANKL/OPG ratio as well as defective COX-2 expression in response to fluid flow in a similar manner to MLOY4 cells cultured under conditions that inhibited the $\alpha_{v} \beta_{3}$ integrin [27]. Although such findings suggest that osteocytes regulation of osteoclasts should be disrupted, the direct effect of altered paracrine signalling from estrogen deficient osteocytes on osteoclastogenesis and osteoclast resorption has never been investigated.

The Wnt antagonist sclerostin (encoded by the SOST gene), produced by mature osteocytes, binds to LRP5/6 Wnt co-receptors, negatively regulates osteoblast proliferation and differentiation via inhibition of the Wnt/ $\beta$-catenin signalling pathway, and also promotes osteocyte and osteoblast apoptosis [33]. Following mechanical loading, $S O S T$ mRNA and sclerostin protein expression are downregulated both in vivo [34] and in vitro in the osteocyte cell line OCY454 [35]. Estrogen has been observed to negatively affect SOST mRNA and sclerostin protein expression in human postmenopausal bone and ovariectomised mice respectively [36, 37]. In contrast to estrogen negatively regulating SOST expression, one study found that SOST expression was reduced in estrogen deficient mice [38]. Thus, the effect of estrogen on SOST expression in vitro is not yet fully understood. There are other known antagonists of the Wnt signalling pathway such as Wnt inhibitory factor 1 (WIF1), Frizzled-related protein $(F R Z B)$ and Secreted frizzled related protein 2 (SFRP2) $[39,40]$. SFRP2 is rapidly downregulated in uterine stromal cells from wild-type (WT) and estrogen receptor $\alpha$ deficient (ER- $\alpha-/-)$ when treated with the estrogen receptor antagonist Fulvestrant [41]. However it is not known whether estrogen also affects expression of other Wnt antagonists in bone cells. Although it has been reported that sclerostin increases RANKL expression in MLO-Y4 cells [42], and $\mathrm{Scl}-\mathrm{Ab}$ treatment is effective for increasing bone formation and reducing bone resorption in OVX animals and postmenopausal women [4, 8-10, 12], how Scl-Ab governs osteocyte regulation of osteoclast differentiation and function is not yet fully understood. Transcriptional profiling of laser capture microdissected osteocytes in bone from rats treated with a single dose of $100 \mathrm{mg} / \mathrm{kg} \mathrm{Scl-Ab}$ revealed early expression changes in regulators of osteoclastogenesis [43]. Specifically, DLX5 (a positive regulator of osteoblastogenesis) was upregulated 72 and $168 \mathrm{~h}$ after receiving the Scl-Ab, WISP1 (a negative regulator of osteoclastogenesis) was also significantly and consistently upregulated following Scl-Ab administration. However, CXCL14 and CXCL12 were downregulated 24 and $168 \mathrm{~h}$ respectively after receiving Scl-Ab [43]. DLX5 knockout mice have displayed increases in osteoclast formation and increased RANKL/OPG expression in osteoblasts [44]. WISP knockout mice revealed that WISP1 is negative 
regulator of osteoclastogenesis and stimulates osteoblasts [45]. CXCL14 is a chemoattractant chemokine for macrophages [46] and CXCL12 binding to its receptor CXCR4 has be shown to promote chemotactic recruitment, development and survival of osteoclasts [47]. In vitro studies have not yet been conducted to understand the biological mechanisms behind sclerostin inhibition and its role in reducing osteocyte-induced osteoclastogenesis and resorption during estrogen deficiency.

In this study the hypotheses that (1) mechanically stimulated osteocytes induce osteoclastogenesis and bone resorption during estrogen deficiency and (2) inhibiting sclerostin reduces osteocyte-induced osteoclastogenesis in vitro, were tested. These studies implement mechanobiology experiments on osteocytes, and their conditioned medium, and osteocytes with BMM or RAW264.7 cells in co-culture to investigate (1) in vitro osteocyte-induced osteoclastogenesis and resorption following loading and estrogen deficiency, (2) changes in osteocyte gene expression of Wnt antagonist's in estrogen and estrogen deficient conditions and (3) whether Scl-Ab administration reverts pro-osteoclastogenic signalling in estrogen deficient osteocytes.

\section{Results}

\section{Estrogen deficiency promotes osteocyte production of soluble pro-osteoclastogenic factors resulting in increased bone resorption. Inhibiting sclerostin can reduce osteoclastogenesis and resorption}

In vitro, osteocytes that have undergone an estrogen withdrawal regime have been shown to have impaired mechanosensation and altered pro-osteoclastogenic mRNA expression (RANKL/OPG, COX-2) [27]. To mimic the conditions observed in estrogen deficiency, osteocytes were subjected to an estrogen withdrawal regime, in which estrogen was withdrawn from the cells that had been accustomed to estrogen for 3 days. Following oscillatory fluid flow, CM was collected and $\mathrm{CM}$ experiments were conducted to investigate the paracrine signalling between mechanically stimulated osteocytes and osteoclast precursors. There was significantly higher TRAP+ cells when BMMs were cultured with CM from estrogen deficient $(\mathrm{ED})$ osteocytes $(p<0.01)$ and also higher levels of TRAP activity $(p<0.0001)$ compared to CM from estrogen treated osteocytes (E) (Fig. 1a, c, d). Bovine bone discs were used to assess the resorptive ability of the differentiated osteoclasts and a significant increase in resorption was observed when BMM cells were cultured with CM from estrogen deficient osteocytes compared to CM from estrogen treated osteocytes $(p<0.0001)$ (Fig. 1b, e). An increase in osteoclastogenesis and TRAP activity was also observed when RAW264.7 cells were treated with CM from estrogen deficient osteocytes compared to estrogen treated osteocytes (Supplementary Figure 1).
Scl-Ab administration in vivo has shown to prevent bone loss induced by mechanical unloading and ovariectomy in a rat model of osteoporosis [4]. Here we examined whether administration of Scl-Ab to estrogen deficient osteocytes in vitro could reduce the increase in osteoclastogenesis observed when BMMs were exposed to $\mathrm{CM}$ from estrogen deficient osteocytes. When estrogentreated osteocytes were treated with Scl-Ab, they produced a CM that decreased osteoclastogenesis $(p<0.05)$ and TRAP activity $(p<0.0001)$ in BMMs further, when compared to estrogen-treated cells that received no SclAb (Fig. 1a, c, d). Similarly, there was a significant decrease in osteoclastogenesis $(p<0.01)$ and TRAP activity $(p<0.0001)$ when BMMs were treated with CM from estrogen deficient osteocytes treated with the Scl-Ab when compared to CM from untreated estrogen deficient osteocytes (Fig. 1a, c, d). Bone resorption by BMM was significantly reduced $(p<0.0001)$ when receiving $\mathrm{CM}$ from osteocytes exposed to $\mathrm{Scl}-\mathrm{Ab}$, when compared to groups receiving $\mathrm{CM}$ from estrogen-treated or estrogen deficient osteocytes with no antibody (Fig. 1b, e). In addition, a two-way ANOVA revealed a significant interaction between the inhibitory effects of estrogen and Scl-Ab on bone resorption ( $p=0.0002$; Fig. 1e). However, analysis by two-way ANOVA revealed no significant interaction between the effects of estrogen and Scl-Ab on osteoclastogenesis or TRAP activity. Increased osteoclastogenesis and TRAP activity was also observed when RAW264.7 cells were treated with $\mathrm{CM}$ from estrogen deficient osteocytes compared to estrogen treated osteocytes. However, CM collected from osteocytes exposed to Scl-Ab did not have the same inhibitory effect on RAW264.7, which was observed in BMM cell cultures (Supplementary Figure 1).

In summary, estrogen deficient and mechanically loaded osteocytes produce soluble factors that increase osteoclastogenesis, TRAP activity and bone resorption when compared to estrogen treated and mechanically loaded osteocytes. However, inhibiting sclerostin reduces pro-osteoclastogenic paracrine signalling between osteocytes and osteoclast pre-cursors (BMM cells) under both estrogen and estrogen deficient conditions.

\section{Estrogen deficient osteocytes treated with $\mathrm{Scl}-\mathrm{Ab}$ produce soluble factors which downregulate CTSK and NFATC1 expression in osteoclasts}

NFATC1 is a master regulator of osteoclast differentiation, and regulates a number of osteoclast specific gene such as TRAP and CTSK [48]. CTSK transcript encodes for cathepsin $\mathrm{K}$, a protease which breaks down type I collagen and therefore plays an important role in bone resorption [49]. We assessed the effects osteocytes CM had on both CTSK and NFATC1 expression in BMM cells. BMM cells upregulated the expression of NFATc1 $(p<0.05)$ following 5 days of culture with $\mathrm{CM}$ from 


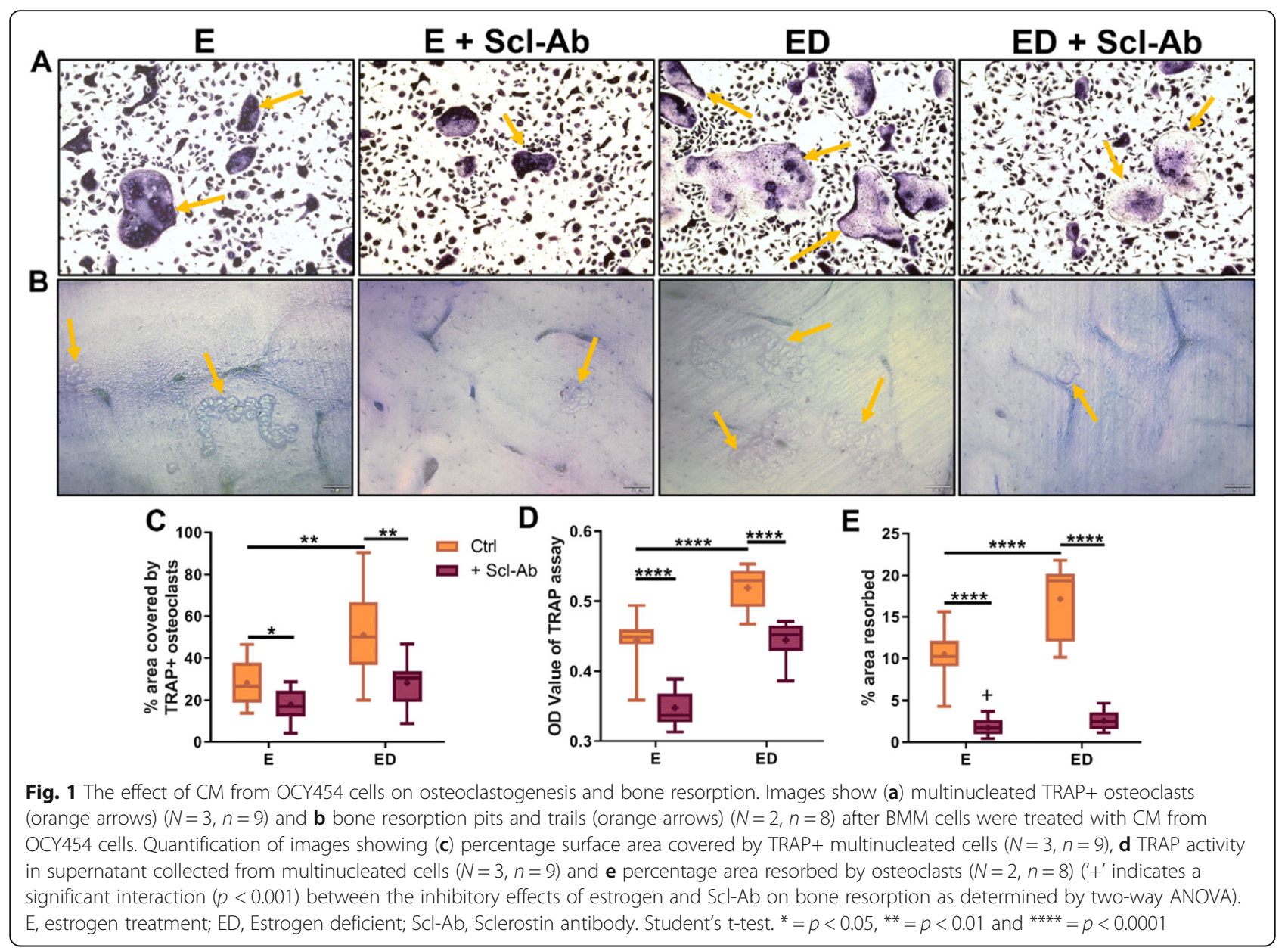

estrogen deficient osteocytes compared to CM from estrogen-treated cells but not CTSK expression ( $p=$ 0.09 ) and (Fig. 2a, b). Supporting the downregulation in bone resorption observed, the CM from osteocytes exposed to Scl-Ab significantly downregulated BMM CTSK expression when compared to the relevant CM from either estrogen-treated or estrogen deficient osteocytes that received no antibody $(p<0.01$ and $p<$ 0.05 respectively) (Fig. 2a). No significant difference in NFATc1 expression was observed when BMM cells were treated with CM from estrogen and Scl-Ab treated osteocytes compared to CM from osteocytes treated with estrogen only. However, a downregulation in NFATc1 expression was observed when BMM cells were treated

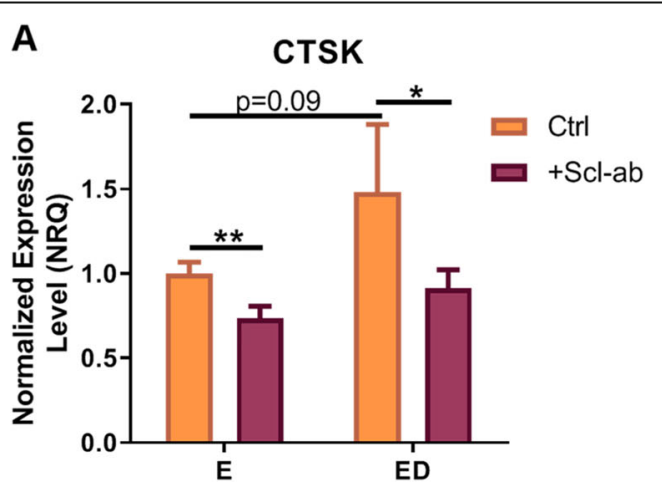

B

NFATc1

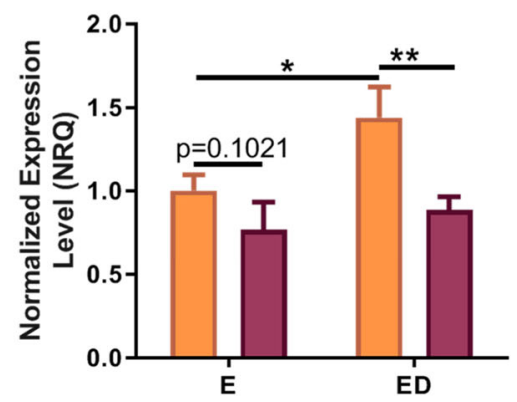

Fig. 2 The effect of CM from OCY454 cells on the expression of osteoclast genes in BMM cells. qRT-PCR analysis of (a) CTSK expression ( $N=3$, $n=9)$ and $\mathbf{b}$ NFATc1 expression $(N=3, n=9)$. E, estrogen treatment; ED, Estrogen deficient; Scl-Ab, Sclerostin antibody. Student's t-test. $=p<0.05$ and ${ }^{* *}=p<0.01$ 
with CM from Scl-Ab treated estrogen deficient osteocytes compared to $\mathrm{CM}$ from untreated estrogen deficient osteocytes $(p<0.01)$ (Fig. 2b). Analysis by two-way ANOVA revealed no significant interaction between the effects of estrogen and Scl-Ab on NFATc1 and CTSK expression. Taken together, estrogen deficient osteocytes treated with $\mathrm{Scl}-\mathrm{Ab}$ produce soluble factors that downregulate the expression of genes necessary for normal osteoclast formation and function.

\section{Estrogen deficient osteocytes that were mechanically stimulated induce osteoclastogenesis in a direct cell-cell contact co-culture system, but in the presence of Scl-Ab osteoclastogenesis is attenuated}

Cell-cell co-culture studies have previously revealed that mechanically stimulated MLO-Y4 cells inhibit osteoclastogenesis in both mouse BMMs and RAW264.7 cells $[25,26]$. However, it is unknown what effect estrogen deficiency has on this process, and for this reason we conducted co-culture studies in which BMM cells were seeded on top of mechanically stimulated osteocytes that had previously received either estrogen treatment or an estrogen withdrawal regime. We report that estrogen deficient osteocytes had an enhanced capacity to induce osteoclast differentiation in BMM cells when compared to estrogen-treated cells $(p<0.05)$ and a concomitant increase in TRAP activity $(p<0.0001)$ was also seen (Fig. 3a, b, c). Co-cultures with RAW264.7 cells produced similar results (Supplementary Figure 2).
We then assessed the effects of inhibiting sclerostin on osteocyte-osteoclast cell-cell signalling. In estrogen treated osteocytes, $\mathrm{Scl}-\mathrm{Ab}$ treatment decreased osteoclastogenesis in BMMs $(p<0.05)$ but had no significant effect on TRAP activity (Fig. 3b, c). Similar results were seen when estrogen treated osteocytes were co-cultured with RAW264.7 cells (Supplementary Figure 2). Administration of Scl-Ab reduced osteoclastogenesis $(p<0.05)$ and TRAP activity $(p<0.0001)$ when BMMs were co-cultured with estrogen deficient osteocytes and indeed these reverted to levels comparable with estrogen-treated co-cultures (Fig. 3b, c). Similar to the CM experiments, analysis by two-way ANOVA revealed no significant interaction between the effects of estrogen and Scl-Ab on osteoclastogenesis or TRAP activity in the co-culture systems.

In summary, mechanically stimulated estrogen deficient osteocytes have an enhanced capacity to induce osteoclastogenesis in a BMM co-culture system, when compared to estrogen-treated osteocytes which have also received mechanical stimulation. However, when estrogen deficient osteocytes are co-cultured with BMM cells in the presence of Scl-Ab, osteoclastogenesis is attenuated.

\section{RANKL/OPG ratio expression is increased in estrogen deficient osteocytes, but this increase is inhibited following Scl-Ab administration}

Osteocytes are the main source of RANKL, a cytokine that induces osteoclastogenesis [50]. We assessed whether the increases in osteoclastogenesis when BMMs
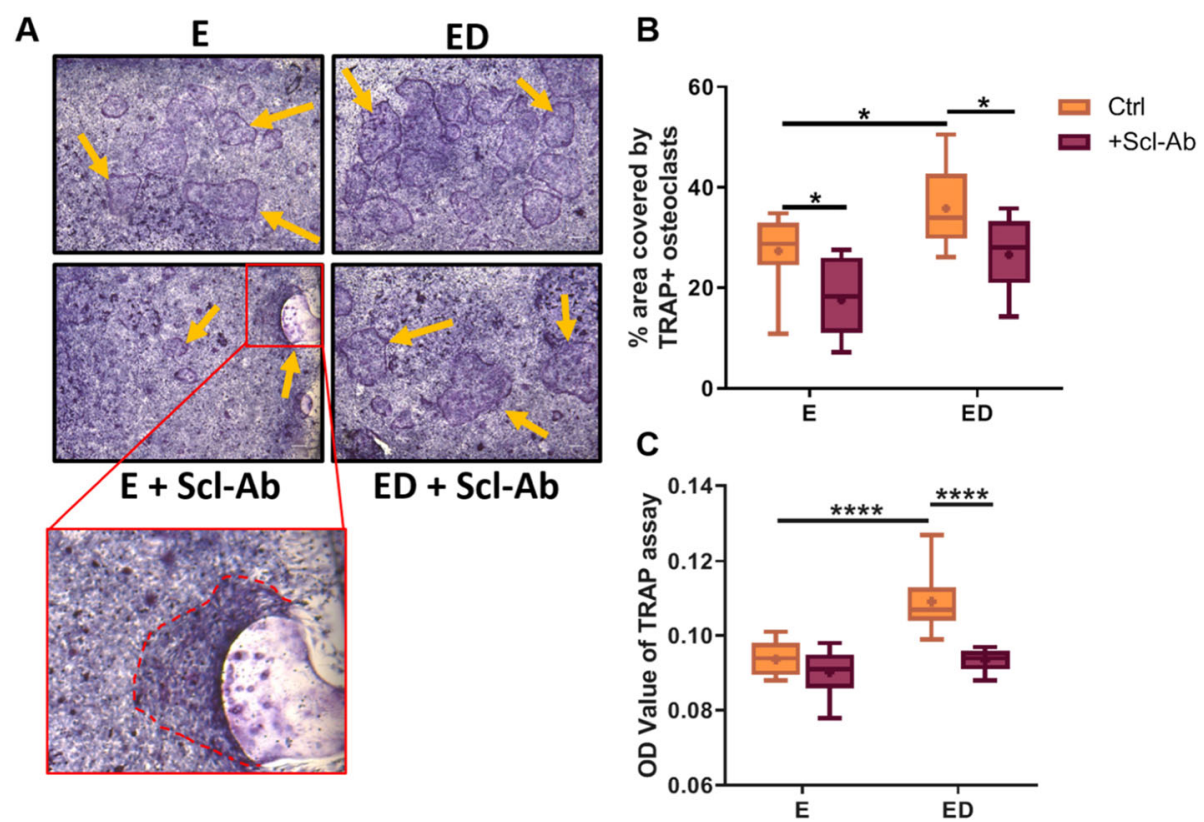

Fig. 3 The effect of sclerostin inhibition on osteocyte induced osteoclastogenesis in a co-culture system. a Images show TRAP+ osteoclasts (orange arrows) formed when BMM cells were co-cultured with OCY454 cells for 6 days. $(N=3, n=9)$. Quantification of images showing (b) percentage area covered by the TRAP+ cells $(N=3, n=9)$ and $\mathbf{c}$ TRAP activity in supernatant collected from OCY454-BMM co-cultures after 6 days $(N=3, n=9)$. E, estrogen treatment; ED, Estrogen deficient; Scl-Ab, Sclerostin antibody. Student's t-test. * $=p<0.05$ and ${ }^{* * *}=p<0.0001$ 
cells were co-cultured with estrogen deficient osteocytes, or it's CM, could be explained by changes in RANKL or $O P G$ expression levels. There was no statistically significant difference in $R A N K L$ or $O P G$ expression levels between estrogen deficient and estrogen-treated osteocytes (Fig. 4a, b). However, the RANKL/OPG ratio increased significantly in estrogen deficient cells compared to estrogen treated osteocytes $(p<0.01)$ (Fig. 4c).

$\mathrm{Scl}-\mathrm{Ab}$ altered the RANKL/OPG ratio in estrogentreated osteocytes; there was a significant downregulation in $R A N K L$ expression $(p<0.01)$ and an upregulation in $O P G$ expression $(p<0.01)$, resulting in a decrease in $R A N K L / O P G$ ratio $(p<0.0001)$ compared to estrogen-treated osteocytes that received no Scl-Ab (Fig. 4a, b, c). Analysis by two-way ANOVA revealed a significant interaction between the effect of estrogen and the effect of Scl-Ab administration on the expression of these genes (RANKL: $p=0.0194$, OPG: $p=$ 0.0012 and RANKL/OPG: $p=0.0118$; Fig. 4). In estrogen deficient osteocytes, Scl-Ab did not alter RANKL or $O P G$ expression individually (Fig. 4a, b). However, the RANKL/OPG ratio was decreased in estrogen deficient osteocytes treated with Scl-Ab compared estrogen deficient osteocytes who received no Scl-Ab treatment $(p<0.05)$ (Fig. 4c).
Taken together, these results demonstrate that estrogen withdrawal leads to an increase in $R A N K L / O P G$ ratio expression compared to estrogen treated osteocytes. However, administration of Scl-Ab to estrogen deficient osteocytes is capable of reducing $R A N K L / O P G$ ratio expression.

\section{Upregulation of CXCL12 an osteoclastogenic regulatory gene in estrogen deficient osteocytes is reversed by Scl- $\mathrm{Ab}$}

Sclerostin inhibition can regulate expression of osteoclast regulators independent of the RANKL-OPG pathway [43]. For this reason, we analysed the mRNA expression of four secreted osteoclastogenic regulatory genes to determine the effect of estrogen deficiency and sclerostin inhibition on their expression. CXCL12 and CXCL14 expression were upregulated in estrogen deficient osteocytes when compared to estrogen treated osteocytes $(p<0.05$ and $p<$ 0.01 respectively) (Fig. $5 \mathrm{a}, \mathrm{b}$ ) but there was no difference in WISP1 and DLX5 expression between estrogen deficient and estrogen treated osteocytes (Fig. 5c, d). In estrogen deficient osteocytes, Scl-Ab downregulated CXCL12 expression $(p<0.05)$ (Fig. 5a). WISP1 expression was upregulated when estrogen treated and estrogen deficient osteocytes were administered with Scl-Ab, when compared

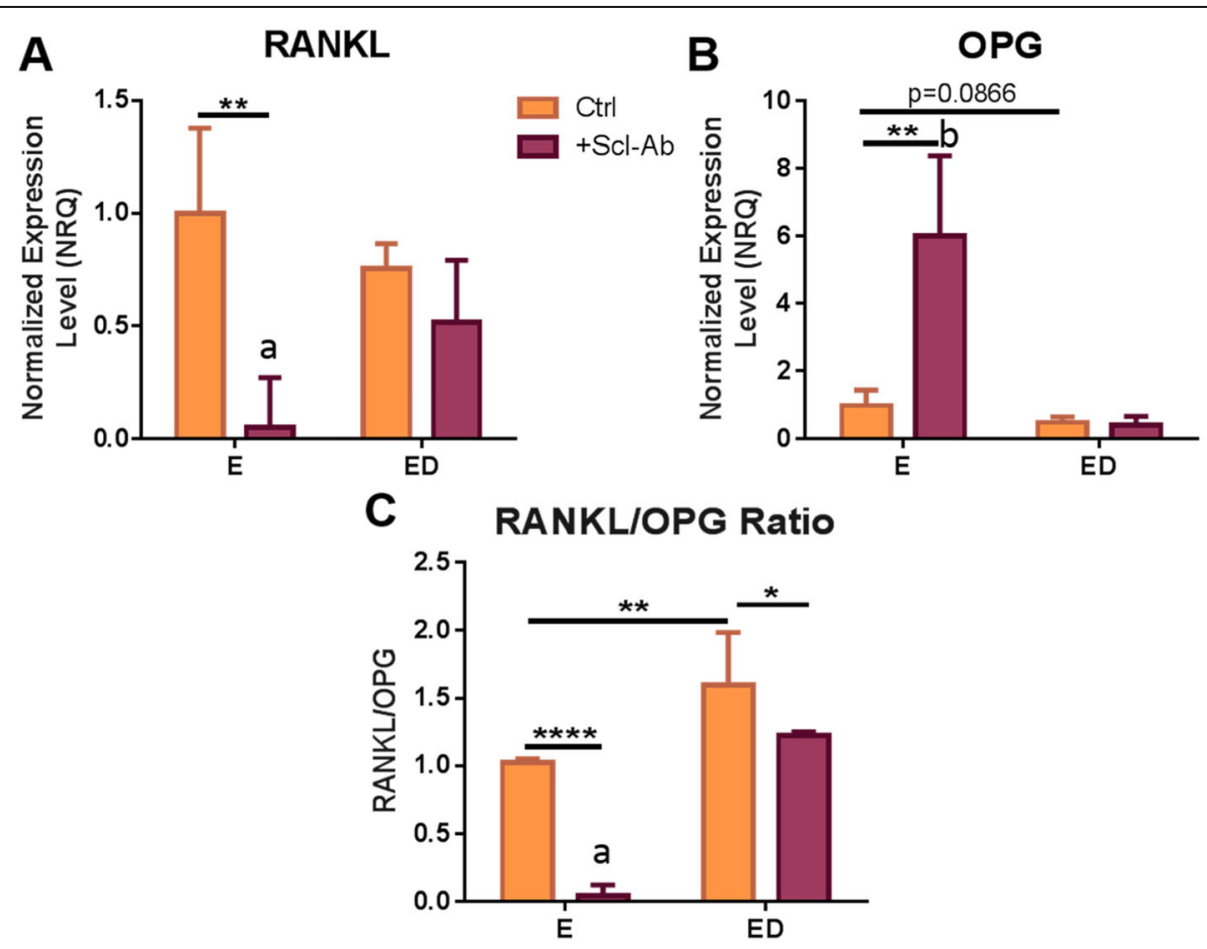

Fig. 4 The effect of estrogen deficiency and sclerostin inhibition on RANKL and OPG gene expression. qRT-PCR analysis of gene expression (relative to estrogen treated group) in OCY454 cells $24 \mathrm{~h}$ after mechanical stimulation (a) RANKL expression $(N=3, n=9)$, b OPG expression ( $N=$ $3, n=9)$ and c RANKL to OPG ratio $(N=3, n=9)$. ('a' and 'b' indicates a significant interaction $(p<0.05$ and $p<0.01$ respectively) between the effects of estrogen and Scl-Ab on RANKL and OPG expression as determined by two-way ANOVA) E, estrogen treatment; ED, Estrogen deficient; Scl-Ab, Sclerostin antibody. Student's t-test. ${ }^{*}=p<0.05,{ }^{* *}=p<0.01$ and ${ }^{* * *}=p<0.0001$ 

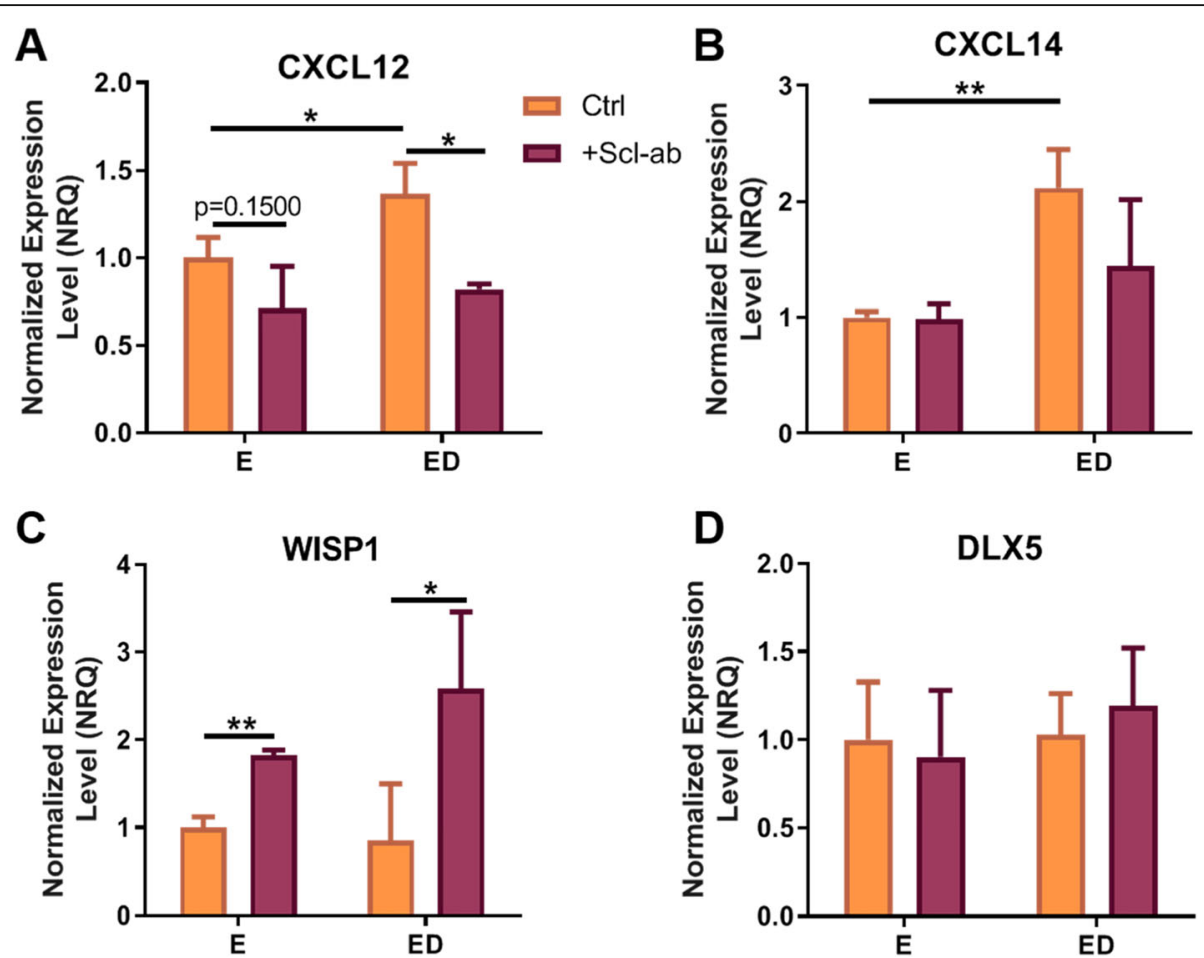

Fig. 5 The effect of estrogen deficiency and sclerostin inhibition on osteocytes expression of osteoclastogenic regulatory genes. QRT-PCR analysis of gene expression (relative to estrogen treated group) in OCY454 cells $24 \mathrm{~h}$ after mechanical stimulation. a CXCL12 expression ( $N=3, n=9), \mathbf{b}$ CXCL14 expression ( $N=3, n=9)$, c WISP1 expression $(N=3, n=9)$ and $\mathbf{d}$ DLX5 expression $(N=3, n=9)$. E, estrogen treatment; ED, Estrogen deficient; Scl-Ab, Sclerostin antibody. Student's t-test. ${ }^{*}=p<0.05$ and ${ }^{* *}=p<0.01$

to untreated groups $(p<0.01$ and $p=0.05)$ (Fig. 5c). However, Scl-Ab had no effect on DLX5 expression in either estrogen treated or estrogen deficient osteocytes (Fig. 5d). Analysis by two-way ANOVA did not detect a significant interaction between the effects of estrogen and Scl-Ab on the expression of these osteoclastogenic regulatory genes.

\section{Estrogen deficiency causes downregulation in the Wnt antagonists FRZB, SFRP2 and WIF1 but upregulates SOST expression in osteocytes}

The canonical Wnt signalling pathway is an important regulator of bone homeostasis. There are a number secreted Wnt antagonists, which can be categorised as those that bind to Wnt ligands and those that bind to the Wnt co-receptor LRP5/6 $[39,40]$. We analysed the mRNA expression of a number of Wnt antagonists including; WIF1, those belonging to the soluble frizzledrelated protein family; SFRP2 and FRZB, as well the gene that encodes for sclerostin; SOST. Under estrogen deficient conditions there was a downregulation in WIF1 $(p<0.05)$ and FRZB $(p<0.05)$ expression compared to estrogen treated osteocytes (Fig. 6a, c). SOST expression was upregulated in estrogen deficient osteocytes compared to estrogen treated osteocytes $(p<0.05)$ (Fig. 6d). Administration of Scl-Ab to estrogen-treated osteocytes downregulated expression of WIF1 $(p<0.05)$ and SFRP2 $(p<0.05)$ but had no effect on FRZB or SOST expression compared estrogen-treated osteocytes that received no Scl-Ab (Fig. 6). However, Scl-Ab had no significant effect of Wnt antagonist expression when administered to estrogen deficient osteocytes (Fig. 6). Analysis by twoway ANOVA did not detect a significant interaction between the effects of estrogen and Scl-Ab on the expression of these Wnt antagonists.

\section{Discussion}

In this study, we exposed osteocytes to oscillatory fluid flow to more accurately represent the in vivo environment and reported for the first time that under estrogen deficiency, a significant increase in osteocyte-induced osteoclastogenesis and resorption occurs compared to estrogen-treated groups. Interestingly, we report that administration of Scl-Ab reduces the RANKL/OPG ratio and upregulates WISP1 gene expression by estrogen deficient osteocytes and these changes are associated with a reduction in osteoclastogenesis by BMM cells in coculture. Scl-Ab exerts similar effects on estrogen treated osteocytes, decreasing osteoclastogenesis in primary BMM cells. In addition, bone resorption is reduced, and both CTSK and NFATc1 gene expression are downregulated in estrogen treated BMM cells following Scl$\mathrm{Ab}$ administration. This study provides an enhanced 

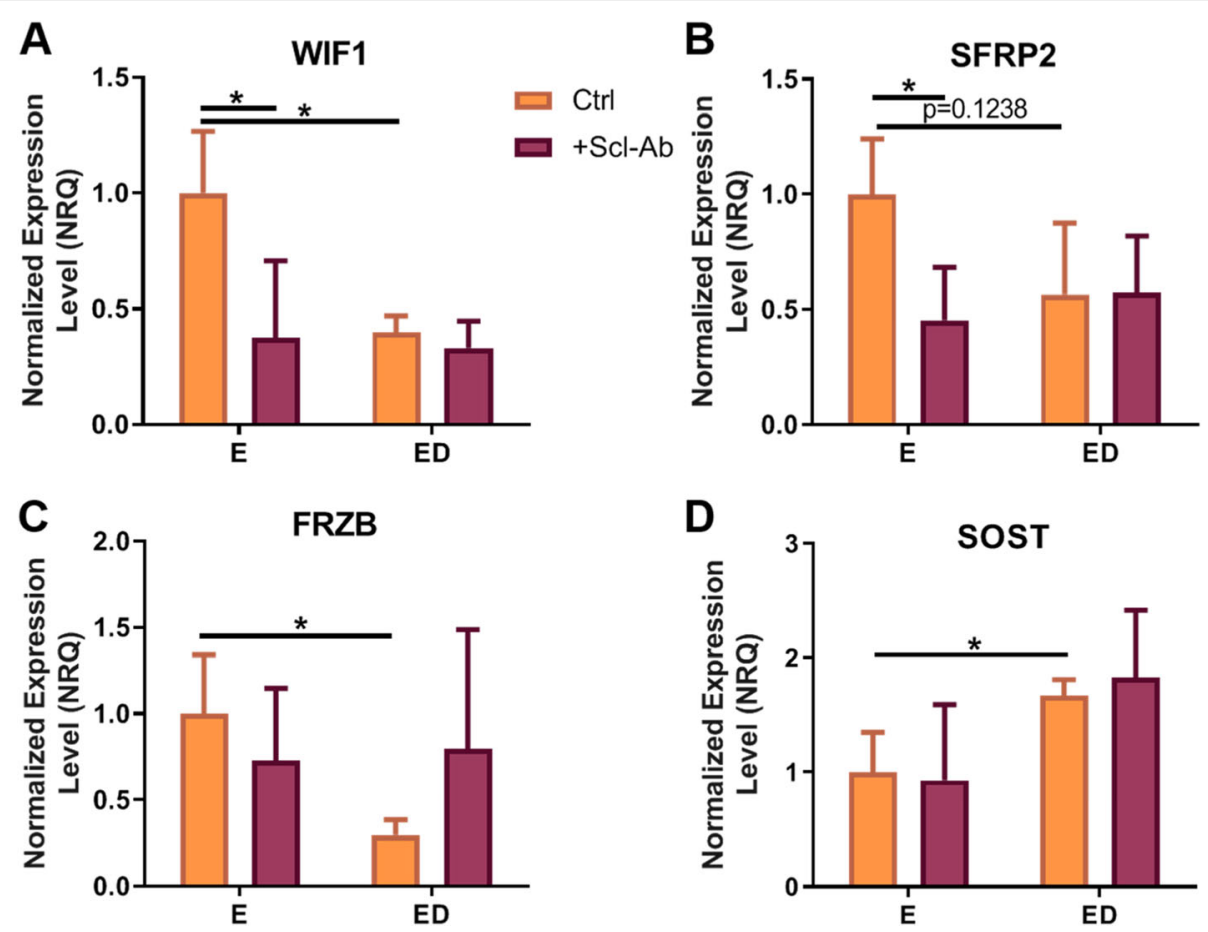

Fig. 6 The effect of estrogen deficiency on Wnt antagonist expression. qRT-PCR analysis of gene expression (relative to estrogen treated group) in OCY454 cells $24 \mathrm{~h}$ after mechanical stimulation. a WIF1 expression $(N=3, n=9)$, b SFRP2 expression $(N=3, n=9), \mathbf{c}$ FRZB expression $(N=3, n=$ 9) and (d) SOST expression $(N=3, n=9)$. E, estrogen treatment; ED, Estrogen deficient; Scl-Ab, Sclerostin antibody. Student's t-test. ${ }^{*}=p<0.05$

understanding of the biological changes underpinning decreases in bone resorption following Scl-Ab treatment observed in vivo by revealing that the Scl-Ab can reduce pro-osteoclastogenic cell signalling between osteocytes and osteoclasts.

There are a number of limitations to this study, which must be addressed. Firstly, the osteocyte cell line OCY454 were used rather than primary osteocytes. OCY454 cells are a relatively new cell line developed by Dr. Pajevic (Boston University), which have been shown to secrete significant levels of soluble sclerostin after they are differentiated [51]. They are also mechanosensitive and have been shown to increase their expression of sclerostin in response to microgravity in vitro [51]. Based on these characteristics, OCY454 cells are a promising candidate to study in vitro effects of sclerostin and mechanical stimulation, and their effects on osteocyteinduced osteoclastogenesis, compared to other osteocyte cell lines, such as MLO-Y4 cells, which express very low levels of sclerostin [51]. Secondly, here all osteocytes were cultured in a monolayer and mechanically stimulated using a parallel plate flow chamber to mimic the in vivo environment more accurately, rather than culturing the osteocytes under static conditions, this is an oversimplification of the stresses experienced by osteocytes in vivo. However, parallel plate flow chambers have been widely used to study osteocyte mechanobiology as they allow downstream chemical events to be easily studied $[26,27,35,52]$. In the clinical setting, Scl-Ab is administered systemically, therefore we treated both OCY454 and BMM cells with Scl-Ab in vitro. Deletion of $\beta$-catenin in osteoclast precursors has been shown to result in an increase in osteoclast number and enhanced resorption. This could suggests that sclerostin might have a direct role in osteoclast differentiation, which is independent of RANKL and OPG [53], however addition of sclerostin to splenocyte or PBMC monocultures had no effect on osteoclastogenesis, indicating that sclerostin does not directly influence these cells [42]. We report differences in osteocyte-mediated differentiation and response to Scl-Ab in RAW264.7 cells and primary BMM cells. Whilst RAW264.7 cells have been used to study osteoclastogenesis for more than 20 years, due to their ease of culture and wide availability, there are differences in cellular programming compared to BMM cells, which have demonstrated a superior ability to resorb bone $[54,55]$. It should also be noted that RAW264.7 cells are derived from adult male BALB/c mice (Abelson leukaemia virusinduced tumor), whereas the BMMs cells were isolated from bone marrow of healthy adult female C57BL/6 mice. Thus sex specific differences may explain the differences observed. Indeed ER $\alpha$ inactivation in female mice resulted in a reduction in load induced bone formation, whereas no effect was observed in male mice [56]. Finally, in vitro 
stimulation of pre- and post-menopausal conditions by the addition or withdrawal of estrogen results in a sudden decrease in estrogen levels, whereas in humans, serum estradiol levels deplete over a 4 year period [57]. Nonetheless, the results show significant and important difference in osteocyte-induced osteoclastogenesis between the continued estrogen administrated and the estrogen deficient groups and thus provide an advanced understanding of role of estrogen status on osteocyte signalling.

It has previously been reported that estrogen deficient MLO-Y4 cells display an increase in RANKL/OPG expression [27], and our study supports this as an increase in $R A N K L / O P G$ ratio in OCY454 cells was also seen. Importantly, we report for the first time here that this increase in $R A N K L / O P G$ ratio resulted in increased osteocyte-induced osteoclastogenesis in primary cells (BMM), and NFATc1 expression was also upregulated, which is a master regulator of osteoclastogenesis [48]. We also report an increase in CXCL14 and CXCL12 expression by estrogen deficient osteocytes, which are regulatory genes that promote chemoattractant recruitment of osteoclasts and their precursors [46, 47]. CXCL12 signalling has also been shown to promote the development and survival of osteoclasts [47]. Therefore, the increases in osteocyte-induced osteoclastogenesis during estrogen deficiency reported here may be explained by changes in RANKL, OPG, CXCL12 and CXCL14 gene expression. Increases in osteocyte-induced osteoclastogenesis in estrogen deficiency occurred through paracrine signalling and through cell-cell contact signalling to similar effects in BMM cells. Although membrane-bound RANKL has been shown to be more potent than soluble RANKL [58], the results presented here suggests that under estrogen deficient conditions this may not be the case. In vitro osteoblast-osteoclast studies previously reported an increase in matrix degradation in estrogen deficient groups compared to estrogen treated group [59]. Here we report a significant increase in bone resorption through use of bovine bone resorption assays, in estrogen deficient groups compared to estrogen treated groups.

Mechanical loading has been shown to downregulate SOST expression by TGF- $\beta$ dependant mechanisms $[34,35,60,61]$. However, here we report that estrogen deficient osteocytes following loading failed to downregulate SOST expression compared to estrogen treated osteocytes. This is contrary to a previous study, which observed a downregulation in SOST expression in estrogen deficient osteocytes exposed to oscillatory fluid flow [28]. It should be noted, that the previous study used MLO-Y4 cells, which express extremely low levels of SOST compared to the OCY454 cells used in this study [51]. However, the upregulation of SOST expression observed here in estrogen deficient OCY454 cells is supported by increases in SOST expression seen in human postmenopausal bone and OVX mice [36, 37]. Interestingly, we report that Wnt antagonists WIF1, SFRP2 and FRZB, which inhibit Wnt signalling by binding to Wnt ligands, were downregulated in estrogen deficiency. Estrogen receptor alpha $(E R \alpha)$, is involved in bone cells adaptive response to mechanical strain [62-65]. Estrogen receptor signalling has demonstrated to work synergistically with Wnt3A to promote osteogenic differentiation [66]. Additionally, activation of $\beta$-catenin and its translocation to the nucleus has been shown to be facilitated by ER $\alpha$ [67]. It has been reported that when estrogen levels are low, or an estrogen receptor antagonist (Fulvestrant) is present, the amount of functional ER $\alpha$ available is reduced, and so there is an insufficient amount of receptors to transduce mechanical strain to biochemical responses [68, 69]. This has been shown to result in reduced accumulation of $\beta$-catenin and therefore a reduction in the transcription of Wnt target genes, leading to a decrease in bone formation [67]. We propose that the decrease in Wnt antagonists (WIF1, SFRP2 and FRZB) act to compensate for the alteration in mechanotransduction seen in estrogen deficiency [67], to promote Wnt signalling and therefore increase activation $\beta$ catenin leading to increased osteogenic responses. Supporting this, MC3T3-E1 cells have been reported to upregulate SFRP1 following mechanical loading [70]. Future studies should investigate whether this response in osteoblastic cells is abrogated in estrogen deficient conditions, similar to what we reported here in osteocytes. Scl-Ab administration down-regulated both WIF1 and SFRP2 expression in estrogen-treated cells, however it appeared to have no significant influence on estrogen deficient cells. This may be a result of our experimental timelines, in which we analysed WNT antagonist expression after only 2 days of Scl$\mathrm{Ab}$ treatment, whereas an in vivo study showed an upregulation in Wnt antagonist expression after 1 week of Scl-Ab administration [71].

Antibodies against sclerostin have demonstrated the ability to promote bone formation leading to increase bone mass and bone strength in both animal studies and clinical trials $[4,8-11]$. Interestingly Scl- $\mathrm{Ab}$ has shown to decrease $R A N K L / O P G$ ratio, osteoclastogenesis in ex vivo cultures from spinal cord injury rat models that undergo bone loss [72]. We report similar effects in terms of osteoclastogenesis, whereby Scl-Ab administration to estrogen deficient osteocytes resulted in a decrease in osteoclastogenesis and resorption, as determined by TRAP staining, TRAP activity, resorption assays and NFATc1 and CTSK expression. This was at least in part due to a decrease in RANKL/OPG 
expression in estrogen deficient osteocytes treated with Scl-Ab. A microarray study of osteocyte-enriched trabecular bone from Scl-Ab treated rats, revealed a decrease in $R A N K L / O P G$ ratio in osteocytes from Scl-Ab treated rats [73]. In addition to this, studies have reported that the Scl-Ab upregulated WISP1 expression in osteocytes, a known negative regulator of osteoclastogenesis $[43,45,73]$. In this study we also report that Scl$\mathrm{Ab}$ administration results in an upregulation of WISP1 expression by both estrogen treated and estrogen deficient osteocytes. Furthermore, CXCL12 expression was downregulated in estrogen deficient osteocytes that received the Scl-Ab, which may decrease the recruitment, development and survival of osteoclasts $[46,47]$. Thus a decrease in RANKL/OPG ratio and CXCL12 expression along with an increase in WISP1 expression following treatment with the Scl-Ab might explain the decrease in osteoclastogenesis and resorption reported here. Scl- $\mathrm{Ab}$ administration was shown to exert similar effects on estrogen treated osteocytes, reducing RANKL/OPG expression and inhibiting osteocyte-induced bone resorption. Analysis of the data (by two-way ANOVA) revealed a significant interaction between estrogen and Scl-Ab administration in terms of the bone resorption, RANKL and $O P G$ expression data; thus it is proposed that estrogen and Scl-Ab synergistically inhibit RANKL/OPG expression and bone resorption. There was no significant interaction between the effects of estrogen and Scl-Ab in terms of TRAP staining, TRAP activity, osteoclastogenic regulatory genes (WISP1, CXCL12, CXCL14, and DLX5) and Wnt antagonists.

\section{Conclusion}

We report that under postmenopausal conditions, an increase in $R A N K L / O P G$ ratio is expressed by osteocytes compared to estrogen-treated osteocytes and a significant increase in osteocyte-induced osteoclast formation occurs leading to increased bone resorption. We demonstrate that in estrogen deficient conditions there is an upregulation of SOST expression but a downregulation in other Wnt antagonists e.g. WIF1, FRZB following mechanical loading, which may indicate a compensatory mechanism for alteration in mechanosensation and mechanotransduction seen in osteocytes. We propose that sclerostin plays an important role in the enhanced pro-osteoclastogenic signalling between osteocyteosteoclast in estrogen deficient conditions. We are the first to show that administration of Scl-Ab reduces proosteoclastogenic signalling between osteocytes and osteoclasts, which leads to reduced bone resorption. This study provides enhanced understanding of the biological changes underpinning reduction in bone resorption seen in animal and clinical studies following Scl-Ab treatment and forms part of the wider mechanism of action of Scl-
$\mathrm{Ab}$, as potent bone-forming agents in severely osteoporotic patients who need rapid increases in bone mineral density to prevent fragility fracture.

\section{Methods \\ Cell culture}

Murine OCY454 osteocyte cells were purchased from the Centre for Skeletal Research Bone Cell Core, an $\mathrm{NIH}$-funded program (P30AR075042), which is supported by NIAMS. OCY454 cells were expanded on type I collagen $(0.15 \mathrm{mg} / \mathrm{ml}$ in $0.02 \mathrm{M}$ acetic acid) coated T175 flasks in $\alpha$-MEM supplemented with $1 \%$ Lglutamine, $2 \%$ antibiotics, and 10\% FBS. OCY454 cells were routinely cultured at the permissive temperature of $33^{\circ} \mathrm{C}$, cells were then trypsinized and placed in noncollagen coated T-175 flasks. After 3 days, cells were differentiated by being transferred to the semi-permissive temperature of $37^{\circ} \mathrm{C}$ for 15 days [51] before being treated with $17 \beta$-estradiol, cells were maintained in a humidified environment at 5\% $\mathrm{CO} 2$.

Osteoclast differentiate from cells of the monocyte/ macrophage lineage [19], based on this bone marrow macrophages (BMM) were isolated from 8 month old female C57BL/6 mice based on [74]. All animal work was carried out under license from the Animal Care and Research Ethics Committee (ACREC) of the National University of Ireland Galway and the Health Products Regulatory Authority (HPRA), the national authority for scientific animal protection in Ireland. Briefly, hind limbs were removed of muscle and tissue, each end of the bone was sectioned, bone marrow aspirate was centrifuged and plated at $5 \times 10^{6}$ cells in $10 \mathrm{~cm}$ bacteriological petri dishes. The bone marrow macrophages were differentiated in the presence of $\alpha$-MEM supplemented with $1 \%$ L-glutamine, $2 \%$ antibiotics, $10 \%$ FBS and 20\% L929 fibroblast cell conditioned media (source of M-CSF). Once macrophages were confluent (approximately 1 week after isolation), cells were trypsinized and scraped, and frozen down or used straight away. BMM cells were used at passage 3 or below. Additionally, RAW264.7 cells were purchased from the American Type Culture Collection (ATCC, Manassas, VA, USA), to assess whether the commonly used male derived cell line responded similarly to primary BMM cells which were isolated from female mice. RAW264.7 cells were expanded in Dulbecco's modified Eagle's medium with 1\% antibiotics, 1\% L-Glutamine, and 10\% heat-inactivated FBS (HyClone). BMM and RAW264.7 cells were cultured in a humidified atmosphere at $37^{\circ} \mathrm{C}$ in $5 \% \mathrm{CO}_{2}$.

\section{Estrogen treatment regimes}

The effect of supplementing culture media with premenopausal levels of estrogen (E) on OCY454 osteocyte behaviour under oscillatory flow conditions in vitro was 
investigated. Following 15 days of expansion in $\alpha$-MEM culture media at $37{ }^{\circ} \mathrm{C}$, OCY454 cells were treated with estrogen (E: $10 \mathrm{nM} 17 \beta$-estradiol) for 6 days. To simulate postmenopausal conditions (ED), we implemented a model that first accustomed osteocytes to estrogen before a subsequent period where estrogen supplementation was discontinued, known as estrogen withdrawal, based on our previous established postmenopausal model using MC3T3-E1 and MLO-Y4 cells [27, 59]. OCY454 cells were treated with $17 \beta$-estradiol $(10 \mathrm{nM})$ for 3 days before it was withdrawn from the media for a further 3 days. In total OCY454 cells were culture at differentiated $37^{\circ} \mathrm{C}$ for 21 days before being exposed to oscillatory fluid flow.

\section{Sclerostin inhibition}

Sclerostin antibody (Scl-Ab VI) was kindly provided by UCB pharma (UCB pharma, UK/Amgen Inc. USA) and was stored at $5 \mathrm{mg} / \mathrm{ml}$ aliquots at $-80^{\circ} \mathrm{C}$. In order to obtain sufficient neutralisation of sclerostin, we treated with $\geq 30 x$ higher concentration than the amount of sclerostin produced by OCY454 cells. A previous study reported that OCY454 cells cultured at $37^{\circ} \mathrm{C}$ for 14 days produce approximately $75 \mathrm{pg} / \mathrm{ml}$ of sclerostin [51], based on this, a non-cytotoxic concentration of $300 \mathrm{ng} / \mathrm{ml}$ was chosen to ensure sufficient sclerostin neutralisation. Untreated groups received PBS as a vehicle, similar to in vivo Scl-Ab studies $[9-11,71,75]$.

\section{Mechanical stimulation}

Osteocytes are the main mechanosensors in bone and are subjected to various forms of mechanical loading $[15,76,77]$. Therefore to capture the in vivo environment more accurately, all osteocytes were subjected to oscillatory fluid flow. Prior to mechanical stimulation OCY454 cells from each of the treatment groups ( $E$ and ED) were seeded at 200,000 cells per collagen coated glass slide $(76 \mathrm{~mm} \times 26 \mathrm{~mm}$ ) (collagen coating was used to prevent cell detachment during fluid flow) and were cultured for a further day either under (a) continued estrogen (E) or (b) estrogen deficient conditions (ED). A subset of these groups, were also treated with $300 \mathrm{ng} / \mathrm{ml}$ $\mathrm{Scl}-\mathrm{Ab}, 24 \mathrm{~h}$ before stimulation. Laminar oscillatory fluid flow was applied to OCY454 cells using a parallel plate system, which comprised of a syringe pump (NE-1600, New Era Pump Systems, Farmingdale, NY, USA), parallel plate chambers and individual media reservoirs connected through gas-permeable silicone tubing (ColeParmer, Vernon Hills, IL, USA) [52]. The OFF loading regime subjected the OCY454 cells to a shear stress of 1 $\mathrm{Pa}$ at $0.5 \mathrm{~Hz}$ for $1 \mathrm{~h}$, which is within the range of shear stresses experiences by osteocytes in vivo [76, 78-80]. Before and after oscillatory fluid flow, slides were rinsed with PBS $(\times 3)$ to remove residual media, to ensure that conditioned media collected did not contain 17 $\beta$ estradiol. After flow, fresh media (without estrogen supplementation) was applied and cells were then cultured for $24 \mathrm{~h}$ before conditioned media was collected for further experiments (described below). Cells treated with Scl-Ab $24 \mathrm{~h}$ prior to flow continued to be treated with $300 \mathrm{ng} / \mathrm{ml} \mathrm{Scl-Ab}$ (i.e. when CM was collected OCY454 cells had been exposed to $300 \mathrm{ng} / \mathrm{ml} \mathrm{Scl-Ab}$ for $48 \mathrm{~h}$ ).

\section{Conditioned media experiments}

Conditioned media from all cell treatment groups (E, E+ $\mathrm{Scl}-\mathrm{Ab}, \mathrm{ED}$ and ED-Scl-Ab) was centrifuged at $1500 \mathrm{rpm}$ and then frozen at $-80^{\circ} \mathrm{C}$ in $1 \mathrm{~mL}$ aliquots. RAW264.7 cells and BMM were seeded at 5000 and 12,000 cells respectively per well in a 96 well plate and then treated with 50\% conditioned media and 50\% expansion media (DMEM). Cells were then cultured in the presence of 15 $\mathrm{ng} / \mathrm{mL}$ of RANKL for 5 days.

\section{Bone resorption assessment}

$6 \mathrm{~mm}$ bone discs with a thickness of between $0.4-0.6 \mathrm{~mm}$ were created from bovine metatarsals based on [81]. Bone discs were soaked in $70 \%$ ethanol and placed in ultrasonic bath (VWR, Dublin, Ireland) at room temperature for 15 min. Prior to culture, discs were sterilised under UV light, BMM cells were seeded on discs at 14,000 cells per discs in a 96 well plate. Cells were cultured with $50 \% \mathrm{CM}$ and $15 \mathrm{ng} / \mathrm{ml}$ RANKL for 10 days, on day 7 concentrated hydrochloric acid (HCL) was added to the culture media to achieve pH 6.9 to induce a more acidic environment necessary for osteoclast resorption [81]. On day 10 the experiment was terminated and cells were removed by sonication in $0.25 \mathrm{M}$ ammonium hydroxide for $5 \mathrm{~min}$. Resorption pits were stained using 1\% Toluidine blue in $1 \%$ sodium borate solution. Images were acquired using a light microscope (Olympus BX43, Olympus, Tokyo, Japan) and quantified using ImageJ software, in which images were colour-thresholded and percentage area resorbed was quantified.

\section{Tartrate-resistant acid phosphatase (TRAP) staining}

At the end of the co-culture and conditioned media experiments RAW 264.7 cells and BMMs were rinsed with PBS and fixed with 4\% Paraformaldehyde. They were then rinsed with PBS and stained for tartrate-resistant acid phosphatase (TRAP) activity with a commercial kit and counterstained with Gill No. 3 hematoxylin for $3 \mathrm{~min}$. Staining was also performed on RAW264.7 and BMM cells, which received expansion media only (negative control) and cells that received expansion media with only supplementation of $15 \mathrm{ng} / \mathrm{mL}$ RANKL (positive control). Images were acquired using a light microscope (Leica DMi1, Leica Biosystems, Wetzlar, Germany) and quantified using ImageJ software, in which images were colour 
thresholded and the percentage area covered by osteoclasts was quantified. TRAP-positive cells with 3 or more nuclei were considered to be osteoclasts.

\section{TRAP activity assay}

At the end of the conditioned media and co-culture experiments, culture media was collected from wells and secreted TRAP activity was detected. The TRAP activity assay involved measuring enzyme activity by the conversion of $\mathrm{p}$ nitrophenylphosphate $(20 \mathrm{nM})$ to $\mathrm{p}$-nitrophenol in the presence of $80 \mathrm{mM}$ sodium tartrate and was expressed as optical density at $405 \mathrm{~nm}$ using a microplate reader (Synergy HT, Biotek Instruments Inc., Winooski, VT, USA).

\section{Co-culture experiments}

Mechanically stimulated OCY454 cells from each group $(\mathrm{E}, \mathrm{E}+\mathrm{Scl}-\mathrm{Ab}, \mathrm{ED}$ and $\mathrm{ED}+\mathrm{Scl}-\mathrm{Ab})$ were seeded at 25 , 000 cells per well in a 48 well plate. After $24 \mathrm{~h}$ RAW264.7 cells were seeded on top of OCY454 cells at 10,000 per well based on a previous study [59] and BMM cells were seeded at 34,000 cells per well. Cells were co-cultured in the presence of $15 \mathrm{ng} / \mathrm{mL}$ of RANK $\mathrm{L}$ for a further 6 days. To mimic systemic administration in humans, Scl-Ab treatment groups continued to receive $300 \mathrm{ng} / \mathrm{ml} \mathrm{Scl-Ab}$ throughout the 6 days of coculture (i.e. both osteocytes and osteoclast precursors were cultured in the presence of Scl-Ab).

\section{qRT-PCR}

BMM cells were exposed to $50 \% \mathrm{CM}$, as described above, and cultured for 5 days. At day 5 mRNA was isolated using High pure RNA isolation kit (Roche Applied Science, Mannheim, Germany). RNA concentration and quality was assessed with a Spectrophotometer/Fluorometer (DS-11 FX, DeNovix, Wilmington, DE, USA)). cDNA was generated using the QuantiNova Reverse Transcription Kit. qRT-PCR was performed on resultant cDNA template on a StepOne plus real-time PCR machine (Applied Biosystems, Foster City, CA, USA) using a QuantiNova SYBR Green PCR Kit and custom designed primers (IDT, Coralville, IA, USA) for Nuclear factor of activated T-Cells cytoplasmic 1 (NFATc1), and Cathepsin K (CTSK) (Primer sequences are shown in Supplementary Table 1).

mRNA from OCY454 cells was isolated $24 \mathrm{~h}$ after exposure to oscillatory fluid flow and transcribed to cDNA using the same protocol as described above. Expression of the following genes were assessed; Receptor activator of nuclear factor kappa-B ligand (RANKL), Osteoprotegerin $(O P G)$, Wnt inhibitory factor 1 (WIF1), Frizzledrelated protein $(F R Z B)$, Secreted frizzled related protein 2 (SFRP2), Sclerostin (SOST), Wnt1-inducible signalling pathway protein-1 (WISP1), C-X-C motif chemokine ligand 12 (CXCL12), C-X-C motif chemokine ligand 14 (CXCL14) and Distal-less homeobox 5 (DLX5) (Primer sequences are shown in Supplementary Table 1). The normalised relative quantities (NRQ) of each sample (BMM and OCY454 samples) were calculated with reference to ribosomal protein large subunit P0 (RPLPO) (Reference gene was identified through qbase+ software). Data was analysed using the Pfaffl method [82].

\section{Statistical analysis}

Data are representative of 3 independent experiments performed in triplicate and are presented as mean \pm SD. Statistical analysis was performed by unpaired two-tailed Student's t-test to examine the effect of estrogen treated groups vs. estrogen deficient groups or Scl-Ab treated group vs. untreated groups. In addition, the interaction between the effects of estrogen and Scl-Ab was also tested though two-way ANOVA analysis. A value of $p<$ 0.05 was regarded as statistically significant. Technical replicates are represented as $\mathrm{N}$, while biological replicates are represented as $n$.

\section{Supplementary Information}

The online version contains supplementary material available at https://doi. org/10.1186/s12860-020-00322-w.

Additional file 1: Supplementary Figure 1. The effect of CM from OCY454 cells on osteoclastogenesis in RAW264.7 cell cultures. Images show (A) multinucleated TRAP+ osteoclasts (orange arrows) $(N=3, n=9)$ after RAW264.7 cells were treated with CM from OCY454 cells.

Quantification of images showing (B) percentage surface area covered by TRAP+ multinucleated cells $(N=3, n=9),(C)$ TRAP activity in supernatant collected from multinucleated cells $(N=3, n=9)$. E, estrogen treatment; $\mathrm{ED}$, Estrogen deficient; Scl-Ab, Sclerostin antibody. Student's t-test. ${ }^{*}=p<$ $0.05,{ }^{* *}=p<0.01$ and ${ }^{* * *}=p<0.0001$. Supplementary Figure 2 . The effect of sclerostin inhibition on osteocyte induced osteoclastogenesis in a co-culture system. (A) Images show TRAP+ osteoclasts (orange arrows) formed when RAW264.7 cells were co-cultured with OCY454 cells for 6 days. $(N=3, n=9)$. Quantifications of images showing (B) percentage area covered by the TRAP+ cells $(N=3, n=9)$ and (C) TRAP activity in supernatant collected from OCY454-RAW264.7 co-cultures after 6 days $(N=3$, $n=9$ ). E, estrogen treatment; ED, Estrogen deficient; Scl-Ab, Sclerostin antibody. Student's t-test. ${ }^{*}=p<0.05,{ }^{* * *}=p<0.001$ and ${ }^{* * *}=p<$ 0.0001. Supplementary Table 1. Primer sequences used in qRT-PCR.

\section{Abbreviations}

TRAP: Tartrate-resistant acid phosphatase; CTSK: Cathepsin K; NFATC1: Nuclear factor of activated T-cells, cytoplasmic 1; BMM: Bone marrow macrophage; Scl-Ab: Sclerostin antibody; LRP 5/6: Low-density lipoprotein receptor-related protein 5/6; OPG: Osteoprotegerin; WIF1: Wnt inhibitory factor 1;

FRZB: Frizzled-related protein; SFRP2: Secreted frizzled related protein 2; SOST: Sclerostin; WISP1: Wnt1-inducible signalling pathway protein-1;

CXCL12: C-X-C motif chemokine ligand 12; CXCL14: C-X-C motif chemokine ligand 14; DLX5: Distal-less homeobox 5; RANKL: Receptor activator of nuclear factor kappaB ligand; E: Estrogen; ED: Estrogen Deficient; OFF: Oscillatory fluid flow; NRQ: Normalised relative quantities; a-MEM: a-minimum essential medium; DMEM: Dulbecco's modified eagle media

\section{Acknowledgements}

The authors acknowledge the facilities and scientific and technical assistance of the Genomics and Screening Core at the National University of Ireland Galway, a facility that is funded by National University of Ireland, Galway and the Irish Government's Programme for Research in Third Level Institutions, Cycles 4 and 5, National Development Plan 2007-2013. The authors thank UCB Pharma/Amgen Inc. for providing Scl-Ab. 


\section{Authors' contributions}

H.A, G.H and L.M.M designed the experiments; H.A conducted the experiments, H.A, and L.M.M analysed the data. All authors wrote and reviewed the manuscript.

\section{Funding}

This publication has emanated from research conducted with financial support of Science Foundation Ireland (SFI) and is co-funded under the European Regional Development fund under grant number 14/IA/2884. The funding body played no role in the design of the study and collection, analysis, interpretation of data or in writing the manuscript.

\section{Availability of data and materials}

The datasets generated during and/or analysed during the current study are available from the corresponding author on reasonable request.

\section{Ethics approval and consent to participate}

All animal work was carried out under license from the Animal Care and Research Ethics Committee (ACREC) of the National University of Ireland Galway and the Health Products Regulatory Authority (HPRA), the national authority for scientific animal protection in Ireland. This study only used material from cell lines and isolation of cells from mice, therefore no consent to participate was required.

\section{Consent for publication}

Not applicable.

\section{Competing interests}

GH is an employee of UCB Pharma and may hold UCB Pharma shares and/or stock options. No conflicts of interest, financial or otherwise, are declared by HA and L.M.M.

\section{Author details}

${ }^{1}$ Mechanobiology and Medical Devices Research Group (MMDRG), Centre for Biomechanics Research (BioMEC), Biomedical Engineering, College of Engineering and Informatics, National University of Ireland Galway, Galway, Ireland. Early Solutions, UCB Pharma, Slough, UK.

Received: 18 August 2020 Accepted: 21 October 2020

\section{Published online: 04 November 2020}

\section{References}

1. Lane NE, Thompson JM, Haupt D, Kimmel DB, Modin G, Kinney JH. Acute changes in trabecular bone connectivity and osteoclast activity in the ovariectomized rat in vivo. J Bone Miner Res. 1998;13(2):229-36.

2. Pavone V, Testa G, Giardina SMC, Vescio A, Restivo DA, Sessa G. Pharmacological therapy of osteoporosis: a systematic current review of literature. Front Pharmacol. 2017:8:803.

3. Murad MH, Drake MT, Mullan RJ, Mauck KF, Stuart LM, Lane MA, Abu Elnour NO, Erwin PJ, Hazem A, Puhan MA, Li T, Montori VM. Clinical review. Comparative effectiveness of drug treatments to prevent fragility fractures: a systematic review and network meta-analysis. J Clin Endocrinol Metab. 2012; 97(6):1871-80.

4. Z Zhang D, Hu M, Chu T, Lin L, Wang J, Li X, Ke HZ, Qin Y-X. Sclerostin antibody prevented progressive bone loss in combined ovariectomized and concurrent functional disuse HHS public access. Bone. 2016;87:161-8.

5. Esbrit P, Herrera S, Portal-Núñez S, Nogués X, Díez-Pérez A. Parathyroid hormone-related protein analogs as osteoporosis therapies. Rev Calcif Tissue Int. 2016, Springer US:98:359-69.

6. Carter PH, Schipani E. The roles of parathyroid hormone and calcitonin in bone remodeling: prospects for novel therapeutics. Endocr Metab Immune Disord Drug Targets. 2006;6(1):59-76.

7. Ominsky MS, Boyce RW, Li X, Ke HZ. Effects of sclerostin antibodies in animal models of osteoporosis. Bone. 2017;96:63-75.

8. Recker RR, Benson CT, Matsumoto T, Bolognese MA, Robins DA, Alam J, Chiang AY, Hu L, Krege JH, Sowa H, Mitlak BH, Myers SL. A randomized, double-blind phase 2 clinical trial of blosozumab, a sclerostin antibody, in postmenopausal women with low bone mineral density. J Bone Miner Res. 2015;30(2):216-24

9. Li X, Niu QT, Warmington KS, Asuncion FJ, Dwyer D, Grisanti M, Han CY, Stolina M, Eschenberg MJ, Kostenuik PJ, Simonet WS, Ominsky MS, Ke HZ.
Progressive increases in bone mass and bone strength in an ovariectomized rat model of osteoporosis after 26 weeks of treatment with a sclerostin antibody. Endocrinology. 2014;155(12):4785-97.

10. Li X, Ominsky MS, Warmington KS, Morony S, Gong J, Cao J, Gao Y, Shalhoub V, Tipton B, Haldankar R, Chen Q, Winters A, Boone T, Geng Z, Niu QT, Ke HZ, Kostenuik PJ, Simonet WS, Lacey DL, Paszty C. Sclerostin antibody treatment increases bone formation, bone mass, and bone strength in a rat model of postmenopausal osteoporosis. J Bone Miner Res. 2009:24(4):578-88.

11. Li X, Ominsky MS, Warmington KS, Niu QT, Asuncion FJ, Barrero M, Dwyer D, Grisanti M, Stolina M, Kostenuik PJ, Simonet WS, Paszty C, Ke HZ. Increased bone formation and bone mass induced by sclerostin antibody is not affected by pretreatment or cotreatment with alendronate in osteopenic, ovariectomized rats. Endocrinology. 2011;152(9):3312-22.

12. Padhi D, Jang G, Stouch B, Fang L, Posvar E. Single-dose, placebocontrolled, randomized study of AMG 785, a sclerostin monoclonal antibody. J Bone Miner Res. 2011;26(1):19-26.

13. Xiao Z, Zhang S, Mahlios J, Zhou G, Magenheimer BS, Guo D, Dallas SL, Maser R, Calvet JP, Bonewald L, Quarles LD. Cilia-like structures and polycystin-1 in osteoblasts/osteocytes and associated abnormalities in skeletogenesis and Runx2 expression. J Biol Chem. 2006;281(41):30884-95.

14. Loiselle AE, Jiang JX, Donahue HJ. Gap junction and hemichannel functions in osteocytes. Bone. 2013;54(2):205-12.

15. Mcnamara LM, Majeska RJ, Weinbaum S, Friedrich V, Schaffler MB. Attachment of osteocyte cell processes to the bone matrix. Anat Rec. 2009; 292(3):355-63.

16. Jaalouk DE, Lammerding J. Mechanotransduction gone awry. Nat Rev Mol Cell Biol. 2009:10(1):63-73.

17. Haj AJE, Minter SL, Rawlinson SCF, Suswillo R, Lanyon LE. Cellular responses to mechanical loading in vitro. J Bone Miner Res. 1990;5(9):923-32.

18. Goldring SR. The osteocyte: key player in regulating bone turnover. RMD Open. 2015;1(Suppl 1):1-4

19. Nakashima T, Hayashi M, Fukunaga T, Kurata K, Oh-Hora M, Feng JQ, Bonewald LF, Kodama T, Wutz A, Wagner EF, Penninger JM, Takayanagi H. Evidence for osteocyte regulation of bone homeostasis through RANKL expression. Nat Med. 2011:17(10):1231-4.

20. Xiong J, Onal M, Jilka RL, Weinstein RS, Manolagas SC, O'Brien CA. Matrixembedded cells control osteoclast formation. Nat Med. 2011;17(10):1235-41.

21. Atkins GJ, Kostakis P, Pan B, Farrugia A, Gronthos S, Evdokiou A, Harrison K, Findlay DM, Zannettino AC. RANKL expression is related to the differentiation state of human osteoblasts. J Bone Miner Res. 2003;18(6):1088-98.

22. Simonet WS, Lacey DL, Dunstan CR, Kelley M, Chang MS, Lüthy R, Nguyen $H Q$, Wooden S, Bennett L, Boone T, Shimamoto G, DeRose M, Elliott R, Colombero A, Tan HL, Trail G, Sullivan J, Davy E, Bucay N, Renshaw-Gegg L, Hughes TM, Hill D, Pattison W, Campbell P, Sander S, Van G, Tarpley J, Derby P, Lee R, Boyle WJ. Osteoprotegerin: a novel se- creted protein involved in the regulation of bone density. Cell. 1997:89:309-19.

23. Nagai M, Sato N. Reciprocal gene expression of osteoclastogenesis inhibitory factor and osteoclast differentiation factor regulates osteoclast formation. Biochem Biophys Res Commun. 1999;257:719-23.

24. Boyce BF, Xing L. The RANKL/RANKJOPG pathway. Curr Osteoporos Rep. 2007;5(3):98-104.

25. You L, Temiyasathit S, Lee P, Hyun C, Tummala P, Yao W, Kingery W, Malone AM. Osteocytes as mechanosensors in the inhibition of bone resorption due to mechanical loading. Bone. 2008:42:172-9.

26. Kulkarni RN, Bakker AD, Everts V, Klein-Nulend J. Inhibition of osteoclastogenesis by mechanically loaded osteocytes: involvement of MEPE. Calcif Tissue Int. 2010;87(5):461-8.

27. Geoghegan IP, Hoey DA, McNamara LM. Estrogen deficiency impairs integrin a $\vee \beta 3$-mediated mechanosensation by osteocytes and alters osteoclastogenic paracrine signalling. Sci Rep. 2019;9:e4654.

28. Deepak V, Kayastha P, McNamara LM. Estrogen deficiency attenuates fluid flow-induced [Ca (2+)]i oscillations and mechanoresponsiveness of MLO-Y4 osteocytes. FASEB J. 2017:31(7):3027-39.

29. Take I, Kobayashi Y, Yamamoto Y, Tsuboi H, Ochi T, Uematsu S, Okafuji N, Kurihara S, Udagawa N, Takahashi N. Prostaglandin E2 strongly inhibits human osteoclast formation. Endocrinology. 2005;146(12):5204-14.

30. Mano M, Arakawa T, Mano H, Nakagawa M, Kaneda T, Kaneko H, Yamada T, Miyata K, Kiyomura H, Kumegawa M, Hakeda Y. Prostaglandin E2 directly inhibits bone-resorbing activity of isolated mature osteoclasts mainly through the EP4 receptor. Calcif Tissue Int. 2000;67:85-92. 
31. Suzuki N, Yoshimura Y, Deyama Y, Suzuki K, Kitagawa Y. Mechanical stress directly suppresses osteoclast differentiation in RAW264.7 cells. Int J Mol Med. 2008;21(3):291-6.

32. Voisin M, McNamara LM. Differential beta3 and beta1 integrin expression in bone marrow and cortical bone of estrogen deficient rats. Anat Rec. 2015; 298(9):1548-59.

33. Holdsworth G, Roberts SJ, Ke HZ. Novel actions of sclerostin on bone. J Mol Endocrinol. 2019;62(2):R167-85.

34. Robling AG, Niziolek PJ, Baldridge LA, Condon KW, Allen MR, Alam I, Mantila SM, Gluhak-Heinrich J, Bellido TM, Harris SE, Turner CH. Mechanical stimulation of bone in vivo reduces osteocyte expression of Sost/sclerostin. J Biol Chem. 2008;283(9):5866-75.

35. Xu LH, Shao H, Ma Y, You L. OCY454 Osteocytes as an in Vitro Cell Model for Bone Remodeling Under Mechanical Loading. J Orthop Res. 2019;37:1681-9.

36. Fujita K, Roforth MM, Demaray S, McGregor U, Kirmani S, McCready LK, Peterson JM, Drake MT, Monroe DG, Khosla S. Effects of estrogen on bone mRNA levels of Sclerostin and other genes relevant to bone metabolism in postmenopausal women. J Clin Endocrinol Metab. 2014;99(1):E81-8.

37. Kim BJ, Bae SJ, Lee SY, Lee YS, Baek JE, Park SY, Lee SH, Koh JM, Kim GS. TNF-a mediates the stimulation of sclerostin expression in an estrogendeficient condition. Biochem Biophys Res Commun. 2012;424(1):170-5.

38. Jastrzebski S, Kalinowski J, Stolina M, Mirza F, Torreggiani E, Kalajzic I, Won HY, Lee S-K, Lorenzo J. Changes in bone sclerostin levels in mice after ovariectomy vary independently of changes in serum sclerostin levels. J Bone Miner Res. 2013;28(3):618-26.

39. Kawano Y, Kypta R. Secreted antagonists of the Wnt signalling pathway. J Cell Sci. 2003;116(Pt 13):2627-34.

40. Cruciat $C M$, Niehrs $C$. Secreted and transmembrane wnt inhibitors and activators. Cold Spring Harb Perspect Biol. 2013;5(3):a015081.

41. Das SK, Tan J, Raja S, Halder J, Paria BC, Dey SK. Estrogen targets genes involved in protein processing, calcium homeostasis, and Wnt signaling in the mouse uterus independent of estrogen receptor-alpha and -beta. J Biol Chem. 2000;275(37):28834-42.

42. Wijenayaka AR, Kogawa M, Lim HP, Bonewald LF, Findlay DM, Atkins GJ. Sclerostin stimulates osteocyte support of osteoclast activity by a RANKLdependent pathway. PLoS One. 2011;6(10):e25900.

43. Nioi P, Taylor S, Hu R, Pacheco E, He YD, Hamadeh H, Paszty C, Pyrah I, Ominsky MS, Boyce RW. Transcriptional profiling of laser capture microdissected subpopulations of the osteoblast lineage provides insight into the early response to Sclerostin antibody in rats. J Bone Miner Res. 2015;30(8):1457-67.

44. Samee N, Geoffroy V, Marty C, Schiltz C, Vieux-Rochas M, Levi G, de Vernejoul MC. Dlx5, a positive regulator of osteoblastogenesis, is essential for osteoblast-osteoclast coupling. Am J Pathol. 2008;173(3):773-80.

45. Maeda A, Ono M, Holmbeck K, Li L, Kilts TM, Kram V, Noonan ML, Yoshioka Y, McNerny EM, Tantillo MA, Kohn DH, Lyons KM, Robey PG, Young MF. WNT1-induced secreted protein-1 (WISP1), a novel regulator of bone turnover and WNT signaling. J Biol Chem. 2015:290(22):14004-18.

46. Yoo HI, Kang JH, Yang SY, Yong JH, Moon JS, Kim MS, Jung JY, Koh JT, Kim WJ, Oh WM, Lee EJ, Kim SH. Differential expression of cxcl-14 during eruptive movement of rat molar germs. J Exp Zool B Mol Dev Evol. 2011;316(6):418-26.

47. Wright LM, Maloney W, Yu X, Kindle L, Collin-Osdoby P, Osdoby P. Stromal cell-derived factor- 1 binding to its chemokine receptor CXCR4 on precursor cells promotes the chemotactic recruitment, development and survival of human osteoclasts. Bone. 2005;36(5):840-53.

48. Kim JH, Kim N. Regulation of NFATC1 in osteoclast differentiation. J Bone Metab. 2014;21(4):233-41.

49. Fonovic M, Turk B. Cysteine cathepsins and extracellular matrix degradation. Biochim Biophys Acta. 2014;1840(8):2560-70.

50. Xiong J, Piemontese M, Onal M, Campbell J, Goellner JJ, Dusevich V, Bonewald L, Manolagas SC, O'Brien CA. Osteocytes, not osteoblasts or lining cells, are the main source of the RANKL required for osteoclast formation in remodeling bone. PLoS One. 2015;10(9):e0138189.

51. Spatz JM, Wein MN, Gooi JH, Qu Y, Garr JL, Liu S, Barry KJ, Uda Y, Lai F, Dedic C, Balcells-Camps M, Kronenberg HM, Babij P, Pajevic PD. The Wnt inhibitor sclerostin is up-regulated by mechanical unloading in osteocytes in vitro. J Biol Chem. 2015;290(27):16744-58.

52. Haugh MG, Vaughan TJ, McNamara LM. The role of integrin $a(V) \beta(3)$ in osteocyte mechanotransduction. J Mech Behav Biomed Mater. 2015:42:67-75.

53. Wei W, Zeve D, Suh JM, Wang X, Du Y, Zerwekh JE, Dechow PC, Graff JM, Wan Y. Biphasic and dosage-dependent regulation of osteoclastogenesis by beta-catenin. Mol Cell Biol. 2011;31(23):4706-19.
54. Levenson EA, Martens C, Kanakabandi K, Turner C, Virtaneva K, Paneru M, Ricklefs S, Sosnovtsev SV, Johnson JA, Porcella SF, Green KY. Comparative transcriptomic response of primary and immortalized macrophage to murine norovirus infection. J Immunol. 2018:200(12):4157-69.

55. Kong L, Smith W, Hao D. Overview of RAW264.7 for osteoclastogensis study: phenotype and stimuli. J Cell Mol Med. 2019;23:3077-87.

56. Callewaert F, Bakker A, Schrooten J, Van Meerbeek B, Verhoeven G, Boonen $\mathrm{S}$, Vanderschueren $\mathrm{D}$. Androgen receptor disruption increases the osteogenic response to mechanical loading in male mice. J Bone Miner Res. 2010;25(1):124-31.

57. Sowers MR, Zheng H, McConnell D, Nan B, Harlow SD, Randolph JF Jr. Estradiol rates of change in relation to the final menstrual period in a population-based cohort of women. J Clin Endocrinol Metab. 2008;93(10):3847-52.

58. Nakashima T, Kobayashi Y, Yamasaki S, Kawakami A, Eguchi K, Sasaki H, Sakai $H$. Protein expression and functional difference of membrane-bound and soluble receptor activator of NF-KB ligand: modulation of the expression by osteotropic factors and cytokines. Biochem Biophys Res Commun. 2000; 275(3):768-75

59. Allison $H$, McNamara LM. Inhibition of osteoclastogenesis by mechanically stimulated osteoblasts is attenuated during estrogen deficiency. Am J Phys Cell Phys. 2019:317(5):969-82.

60. Nguyen J, Tang SY, Nguyen D, Alliston T. Load regulates bone formation and Sclerostin expression through a TGFß-dependent mechanism. PLoS One. 2013;8(1):e53813.

61. Robling AG, Bellido T, Turner $\mathrm{CH}$. Mechanical stimulation in vivo reduces osteocyte expression of sclerostin. J Musculoskelet Neuronal Interact. 2006; 6(4):354.

62. Damien E, Price JS, Lanyon LE. Mechanical strain stimulates osteoblast proliferation through the estrogen receptor in males as well as females. J Bone Miner Res. 2000;15(11):2169-77.

63. Galea GL, Price JS, Lanyon LE. Estrogen receptors' roles in the control of mechanically adaptive bone (re)modeling. Bonekey Rep. 2013;2(SEPTEMBER):413.

64. Damien E, Price JS, Lanyon LE. The estrogen receptor's involvement in osteoblasts' adaptive response to mechanical strain. J Bone Miner Res. 1998; 13(8):1275-82.

65. Zaman G, Jessop HL, Muzylak M, De Souza RL, Pitsillides AA, Price JS, Lanyon LL. Osteocytes use estrogen receptor alpha to respond to strain but their ERalpha content is regulated by estrogen. J Bone Miner Res. 2006; 21(8):1297-306.

66. Gao Y, Huang E, Zhang H, Wang J, Wu N, Chen X, Wang N, Wen S, Nan G, Deng F, Liao Z, Wu D, Zhang B, Zhang J, Haydon RC, Luu HH, Shi LL, He TC. Crosstalk between $\mathrm{Wnt} / \beta$-catenin and estrogen receptor signaling synergistically promotes osteogenic differentiation of mesenchymal progenitor cells. PLoS One. 2013;8(12):e82436.

67. Armstrong VJ, Muzylak M, Sunters A, Zaman G, Saxon LK, Price JS, Lanyon LE. Wnt/beta-catenin signaling is a component of osteoblastic bone cell early responses to load-bearing and requires estrogen receptor alpha. J Biol Chem. 2007;282(28):20715-27.

68. Pinzone JJ, Stevenson H, Strobl JS, Berg PE. Molecular and cellular determinants of estrogen receptor alpha expression. Mol Cell Biol. 2004;24 4605-12.

69. Chow SK, Leung KS, Qin J, Guo A, Sun M, Qin L, Cheung WH. Mechanical stimulation enhanced estrogen receptor expression and callus formation in diaphyseal long bone fracture healing in ovariectomy-induced osteoporotic rats. Osteoporos Int. 2016;27(10):2989-3000

70. Robinson JA, Chatterjee-Kishore M, Yaworsky PJ, Cullen DM, Zhao W, Li C, Kharode $Y$, Sauter L, Babij P, Brown EL, Hill AA, Akhter MP, Johnson ML, Recker RR, Komm BS, Bex FJ. Wnt/beta-catenin signaling is a normal physiological response to mechanical loading in bone. J Biol Chem. 2006: 281(42):31720-8.

71. Holdsworth G, Greenslade K, Jose J, Stencel Z, Kirby H, Moore A, Ke HZ, Robinson MK. Dampening of the bone formation response following repeat dosing with sclerostin antibody in mice is associated with up-regulation of Wnt antagonists. Bone. 2018;107:93-103.

72. Qin W, Li X, Peng Y, Harlow LM, Ren Y, Wu Y, Li J, Qin Y, Sun J, Zheng S, Brown T, Feng JQ, Ke HZ, Bauman WA, Cardozo CC. Sclerostin antibody preserves the morphology and structure of osteocytes and blocks the severe skeletal deterioration after motor-complete spinal cord injury in rats. J Bone Miner Res. 2015;30(11):1994-2004.

73. Taylor S, Ominsky MS, Hu R, Pacheco E, He YD, Brown DL, Aguirre JI, Wronski TJ, Buntich S, Afshari CA, Pyrah I, Nioi P, Boyce RW. Time- 
dependent cellular and transcriptional changes in the osteoblast lineage associated with sclerostin antibody treatment in ovariectomized rats. Bone. 2016;84:148-59.

74. Weischenfeldt J, Porse B. Bone marrow-derived macrophages (BMM): isolation and applications. CSH Protoc. 2008;3(12):1-7.

75. Ominsky MS, Boyd SK, Varela A, Jolette J, Felx M, Doyle N, Mellal N, Smith SY, Locher K, Buntich S, Pyrah I, Boyce RW. Romosozumab improves bone mass and strength while maintaining bone quality in ovariectomized cynomolgus monkeys. J Bone Miner Res. 2017;32:788-801.

76. Wang Y, McNamara LM, Schaffler MB, Weinbaum S. A model for the role of integrins in flow induced mechanotransduction in osteyocytes. Bioeng Proc Northeast Conf. 2007;104(40):39-40

77. Klein-Nulend J, Bacabac RG, Bakker AD. Mechanical loading and how it affects bone cells: the role of the osteocyte cytoskeleton in maintaining our skeleton. Eur Cell Mater. 2012;24:278-91.

78. Han Y, Cowin SC, Schaffler MB, Weinbaum S. Mechanotransduction and strain amplification in osteocyte cell processes. Proc Natl Acad Sci. 2004;101: 16689-94

79. Verbruggen SW, Vaughan TJ, MCNamara LM. Strain amplification in bone mechanobiology: a computational investigation of the in vivo mechanics of osteocytes. J R Soc Interface. 2012;9(75):2735-44.

80. Weinbaum S, Cowin SC, Zeng Y. A model for the excitation of osteocytes by mechanical loading-induced bone fluid shear stresses. J Biomech. 1994; 27(3):339-60.

81. Orriss IR, Arnett TR. Rodent osteoclast cultures. In: Helfrich MH, Ralston SH, editors. Bone research protocols. Totowa: Humana Press; 2012

82. Pfaffl MW. A new mathematical model for relative quantification in real-time RT-PCR. Nucleic Acids Res. 2001;29:e45.

\section{Publisher's Note}

Springer Nature remains neutral with regard to jurisdictional claims in published maps and institutional affiliations.

Ready to submit your research? Choose BMC and benefit from:

- fast, convenient online submission

- thorough peer review by experienced researchers in your field

- rapid publication on acceptance

- support for research data, including large and complex data types

- gold Open Access which fosters wider collaboration and increased citations

- maximum visibility for your research: over $100 \mathrm{M}$ website views per year

At $\mathrm{BMC}$, research is always in progress.

Learn more biomedcentral.com/submissions 